http://rev.med.panacea.unica.edu.pe

Rev méd panacea. 2014; 4(3):81.

Recibido: 19 de Octubre del 2014 | Aceptado: 15 de Noviembre del 2014 | Publicado: 31 de Diciembre del 2014

CONFICTO DE INTERES: NO DECLARADOS

CARTA AL EDITOR

\title{
La responsabilidad institucional de administrar una revista científica
}

\author{
THE INSTITUTIONAL RESPONSIBILITY OF MANAGING A SCIENTIFIC JOURNAL
}

\author{
Alfredo Enrique Oyola-García ${ }^{\text {1a }}$ \\ Natural and Social Sciences Research ${ }^{1}$ \\ Medico ${ }^{\mathrm{a}}$
}

\section{Sr. Editor}

$\mathrm{H}$ ace unos años Torres Godomar (1), docente y ex Decano de la Facultad de Medicina de la Universidad Nacional San Luis Gonzaga señalaba: "La tarea de publicar una revista científica es ardua y a menudo ingrata e incomprendida, no valorando que ésta representa una gran oportunidad para que nuestros docentes, alumnos y egresados demos a conocer nuestra producción intelectual a la familia médica regional y nacional". Hoy se puede decir, con toda seguridad, que esa apreciación no era exagerada.

En publicaciones previas de su revista se leía con entusiasmo que una de las aspiraciones era estar al nivel de las mejores revistas del país al cumplir ciertos requisitos (indización, periodicidad, visibilidad, calidad, etc.) $(2,3)$ y contar con un sistema que garantice la publicación en línea, entre otros (2). Sin embargo, este anhelo no será posible, puesto que a la fecha no se han publicado los números correspondientes año 2013(4). Esta situación afecta dramáticamente la visibilidad de la revista y podría alejar a los investigadores interesados en comunicar -a través de ella- sus hallazgos (5) debido a que la publicación tardía trae como consecuencia la obsolescencia de los resultados, además de generar desconfianza de los investigadores para una nueva publicación por la baja visibilidad de los lectores y el elevado riesgo de cometer una falta ética al realizar una publicación redundante cuando no se recibe información del estado del artículo en la revista por la ausencia de procedimientos administrativos sostenibles.

Este problema no es exclusivo de la Revista Médica Panacea. Las revistas médicas nacionales desaparecen, salen tardíamente o no cumplen con los estándares internacionales como lo señalaba Pamo (6). No obstante, es necesario tomar medidas urgentes para actuar sobre esta problemática que podría estar relacionada con el declive en la participación en Congresos Científicos Nacionales de Estudiantes de Medicina (7) y la escasa publicación docente en revistas científicas nacionales o internacionales (8). ¿Acaso el fomento de la investigación y su comunicación no es un tema de importancia para la universidad?

Administrar la revista es una responsabilidad y, por experiencia personal, si no se cuenta con recursos humanos, económicos, financieros y logísticos permanentes, no se logrará su sostenibilidad. En consecuencia, urge establecer una mesa de trabajo institucional que identifique y proponga estrategias para lograrla teniendo como guía las propuestas que Pamo (6) nos menciona. Responsabilidad que debe asumir la universidad y, por consiguiente, la Facultad de Medicina "Daniel Alcides Carrión" para que la Revista Médica Panacea no vuelva a caer en el cofre del olvido.

Autor Corresponsal: Alfredo Enrique Oyola García. Dirección: C.H. A. Valdelomar C-201, Urb. Sta. Rosa del Palmar. Ica, Perú . Teléfono: (51)956124996. Correo electronico: aoyola@redmed-ica.com .

\section{REFERENCIAS BIBLIOGRÁFICAS}

1. Torres Godomar R. Editorial. Rev. méd. panacea (internet). 2011 (citado 19 oct 2014); 1(3):58. [Link]

2. Ybaseta-Medina J, Alarco JJ. La iniciativa Open Journal Sistem (OJS) y su implementación en la Revista Médica Panacea. Rev. méd. panacea. (1 ventana. 2012 (citado 19 oct 2014); 2(2): 31-32. [Link]

3. Arroyo H, Ybaseta J. Editorial. Rev. méd. panacea. (internet). 2011 (citado 19 oct 2014); 1(2):27. [Link]

4. Revista Médica Panacea: Archivos (internet). Ica: Universidad Nacional San Luis Gonzaga de Ica. (citado 19 oct 2014). [Link]

5. Miyahira J. Editorial. Rev. méd. panacea. (internet). 2012 (citado 19 oct 2014); 2(1):1. [Link]

6. Pamo OG. Estado actual de las publicaciones periódicas científicas médicas del Perú. Rev Med Hered (internet). 2005 (citado 19 oct 2014); 16 (1):65-73. [Link]

7. Alarco JJ, Álvarez-Andrade EV. Nuestra participación en los congresos científicos nacionales de estudiantes de medicina, 1993 -2010. Rev. méd. panacea (internet). 2011 (citado 19 oct 2014); 1(1):22-23. [Link]

8. Arroyo-Hernández H, Zukerán-Medina B, Miranda-Soberón UE. Análisis bibliométrico de la producción científica biomédica en la Región de Ica, Perú. 1988-2010. Rev. méd. panacea (internet). 2011 (citado 19 oct 2014); 1(1):2-8. [Link]
CITA SUGERIDA.

Oyola-Garcia AE. La responsabilidad institucional de administrar una revista científica. Rev méd panacea.2014; 4(3):81. 